Original Contribution

\title{
COMPARATIVE INVESTIGATION OF EGG PRODUCTION IN WG, GG AND GL JAPANESE QUAIL POPULATIONS
}

\author{
H. Lukanov*, A. Genchev, P. Kolev \\ Faculty of Agriculture, Trakia University, Stara Zagora, Bulgaria
}

\begin{abstract}
The aim of the study was to evaluate egg production in three heavy Japanese quail populations created and reared in the Poultry Breeding Unit of the Trakia University - Bulgaria, marked as WG, GG and GL. In the experiments, 160 female birds from populations WG and GG, and 96 female birds from population GL were tested up to the 6th production month. The main egg production traits were controlled. The highest egg production for the period was demonstrated in group GL $(79.84 \pm 4.46 \%)$, followed by group GG $(76.33 \pm 3.40 \%)$ and group WG $(72.11 \pm 4.16 \%)$. Quails from the WG group were outlined with least efficient feed conversion per egg $(74.49 \pm 1.21 \mathrm{~g}$ feed), while those from the GL group: with the most efficient one $-64.93 \pm 1.41 \mathrm{~g}(\mathrm{p}<0.01)$. The highest average egg weight in descending order was observed in the WG group (14.04 $\pm 0.32 \mathrm{~g})$, GG group (13.65 $\pm 0.27 \mathrm{~g})$ and GL group $(12.79 \pm 0.29 \mathrm{~g})$. The Japanese quail populations created and maintained at the Trakia University showed a potentially good egg production for the production type they belonged to, which makes them attractive for use in interline hybridisation schedules, including for production of autosexing stock layers.
\end{abstract}

Key words: Coturnix japonica, egg production, meat type, feed conversion, laying intensity.

\section{INTRODUCTION}

Domesticated quails originate from the wild Japanese quail (Coturnix japonica, Temminck \& Schlegel, 1849). Wild quails are reared in East and South-east Asia as singing and decorative birds since the antiquity. The domestication of quails occurred in Japan for a very short period by the end of the 19th century and the early 1900ies. According to Howes (1) the selection of Japanese quails for higher egg production began during the second half of the 19th century. The high egg production benefited from the fact that the brooding instinct in the population was eradiated. During the second half of the 19th century, domesticated quails spread to Europe, the Near East and Central Asia, along with beginning of their industrial rearing (2). Now, the only two domestic fowl species producing

\footnotetext{
*Correspondence to: Hristo Lukanov, PhD; Department of Animal Science - monogastric and other animals, Faculty of Agriculture, Trakia University,6000 Stara Zagora, Bulgaria, dr_lukanov@abv.bg
}

stocking eggs at a global scale are the domestic chicken and the Japanese quail. Apart being a production bird species, domesticated quails are also used as laboratory and decorative birds.

The main products obtained from domestic quails are stock/breeder eggs and meat. Additional products could be dehydrated manure or biogas (3-5).

Domesticated Japanese quail is outlined with earliest onset of sexual maturity among livestock species, attaining maturity at 35-42 days of age. Annually, one female lays down 280 eggs on the average, with weight of 10-16 g. The difference in the weight of eggs is proportional to the live weight of layers. Depending on the production type, the live weight of quails varies within a broad range from 120-140 to 400-450 $\mathrm{g}$ (6). The production could be fully automated, which is favourable for the development of the sector. The lower initial investments for starting production, the most efficient use of building stock due to the higher housing density of birds, the early onset 
of sexual maturity and high productivity are a background for rapid return of inputs. All these facts are serious reasons for explaining the large-scale and fast introduction of the species in the world livestock production practices. The increase in the global production of quail eggs and meat is mainly due to the increasing demands. The consumers in many countries are well informed about the valuable traits of this produce.

Three heavy-type Japanese quail populations are created and reared in the Poultry Breeding Unit of the Trakia University - Bulgaria, designated as WG, GG and GL. The first two genotypes, as well as autosexing hybrids with the participation of the GL line are extensively used in national farms for stocking eggs and fattening birds production.

The aim of this study was to investigated the egg production of the three heavy Japanese quail populations created and reared in the Poultry Breeding Unit of the Trakia University.

\section{MATERIAL AND METHODS}

The egg production of three Japanese quail population created and reared in the Poultry Breeding Unit of the Trakia University was evaluated. They comprised two heavy populations with wild and golden plumage, designated as WG and GG and one dualpurpose population with cinnamon plumage GL (Figure 1). In the experiments, 160 female birds from populations $\mathrm{WG}$ and GG, and 96 birds from population GL were used. At 35 days of age, the birds were allotted in 10 subgroups with 16 birds each from WG and GG types, and 6 subgroups with 16 GL quails. The birds were reared in batteries in compliance with all hygiene requirements for the species and production type.
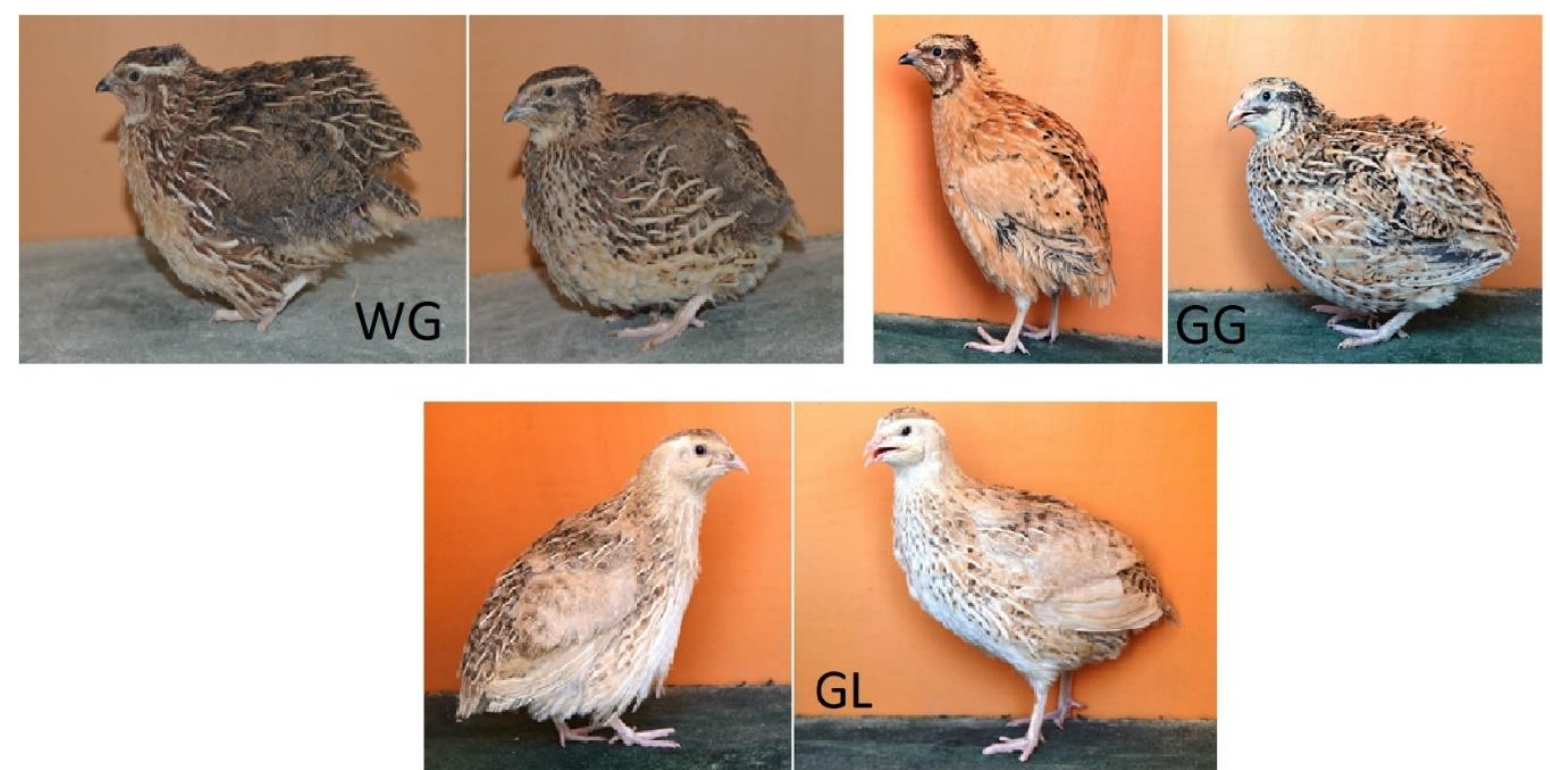

Figure 1. Sexually mature Japanese quails from the WG, GG and GL populations.

The quails were reared under constant 16-hour light day from 35 days of age to the end of the 6 th production month.

Feeding was uniform throughout the experiment with the following composition of the compound feed: ME: $11.5 \mathrm{MJ} / \mathrm{kg}$; CP: $19.5 \%$; lysine: $1.0 \%$; methionine+cysteine: $0.75 \%$; calcium: $2.8 \%$; available phosphorus: $0.45 \%$, and optimum levels of vitamins and minerals.

As $50 \%$ egg production was attained, all birds were individually weighed on a CB 2000 balance with precision of $0.01 \mathrm{~g}$, including male birds which were separately housed.
The control on egg production was performed by daily monitoring of the number of laid eggs from each subgroup and differentiation of standard eggs (those with normal size, shape, integrity and shell colour for the age) from culled eggs. The group of the latter included double-yolk eggs, eggs with soft shell or without shell, and those with various deviations in the size, shape, shell exterior, shell integrity, depigmented eggs and those with considerable deviations in the pigmentation. On the basis of monitoring, the lay intensity of the flock and culled eggs percentage were determined on weekly and monthly basis. 
Twice within each production month, the 3day yield of eggs from all nests was individually weighed on a CB 2000 balance with precision of $0.01 \mathrm{~g}$. Parallelly, feed consumption was recorded. The results were used for calculation of average daily feed intake and feed conversion for one egg and for 1 g egg mass.

The physiological condition and health of birds was controlled daily by inspection when the number of laid eggs was recorded. The inspection included monitoring of death rate and culled birds under the category "dead and culled birds".

All data were processed with statistical software Statistica 13.0 (Statistica for Windows; Stat - Soft, 2015). Mean (x), standard error of mean (SEM) and coefficient of variation $(\mathrm{CV}, \%)$ values were calculated for each group. The differences considered statistically significant at $\mathrm{p}<0.05$, using Student's t-test, if the data were normally distributed.

\section{RESULTS AND DISCUSSION}

The live weight of domestic quails varies largely depending on the production type egg-type, dual-purpose or meat-type. Figure 2 presents data for average live weight of sexually mature males and females from the three populations. The highest mean weight was established in group WG, which was the heaviest among the three: $346.3 \pm 2.71 \mathrm{~g}$ for females and $282.02 \pm 2.75 \mathrm{~g}$ in males. Then came the other meat-type population GG $(334.21 \pm 2.85 \mathrm{~g}$ and $275.54 \pm 2.69 \mathrm{~g})$. The lightest population was GL, an all-purpose type with weights of $294.69 \pm 4.72 \mathrm{~g}$ and $244.58 \pm 4.65 \mathrm{~g}$ for females and males, respectively. Compared to the heaviest $\mathrm{WG}$ group, female GG quails weighed by $3.49 \%$ less and males: by $2.3 \%$ less, while both sexes from the GL population were by $14.90 \%$ and $13.28 \%$ lighter. In all groups, males having attained maturity were lighter than females. This difference varied from $18.56 \%$ (WG group) to $17 \%$ (GL group). It is normal for the species and is attributed to the higher energy expenditure by sexually mature males and the development of female genital system. With age, the sex-related difference in the live weight becomes even more pronounced (6). In a study on production traits of $\mathrm{WG}$ and $\mathrm{GG}$ ancestors, Genchev (2) demonstrated rather lower body weights in mature birds. These variations could be explained with the prolonged selection for live weight, whose dynamics could be partly observed in the cited research. The detected average weight in both sexes of the GL population was comparable to that reported in an earlier study of ours on exterior traits of the population (7).

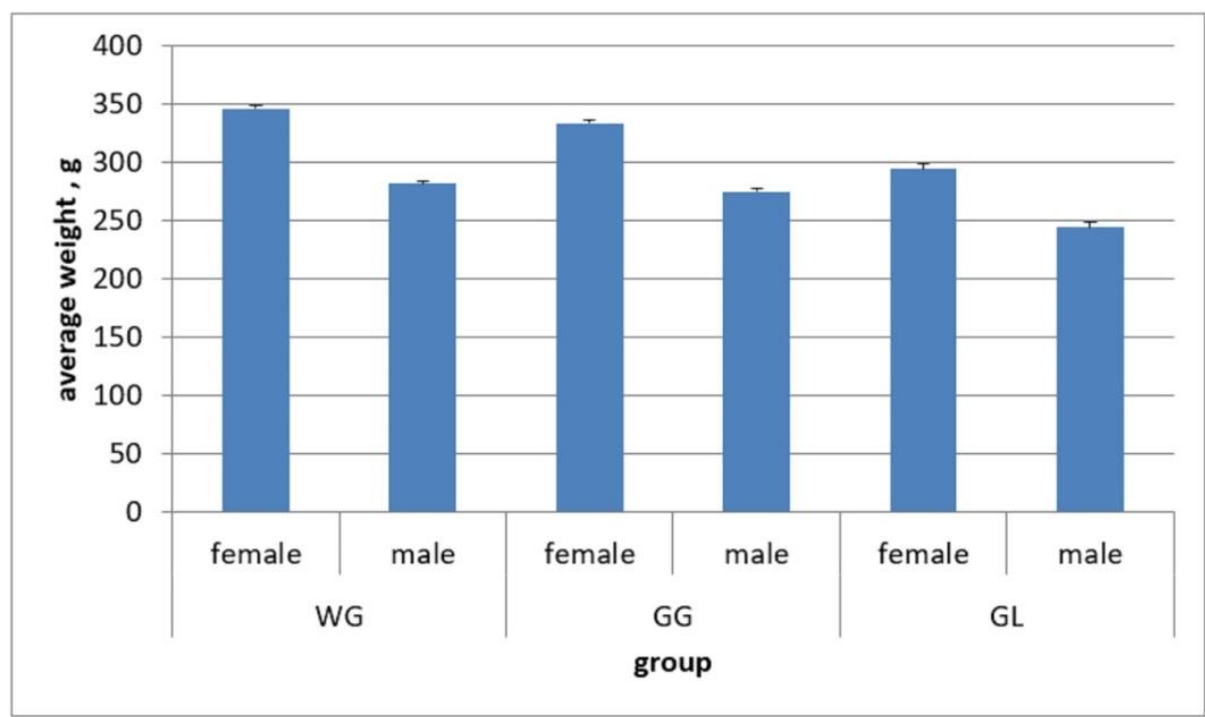

Figure 2. Average weight (g) of both sexes from WG, GG and GL populations at $50 \%$ egg production.

Quails could be used for production of breeder or stock eggs over 6-12 production months depending on the type, purpose and production system. In our conditions, the production cycle of birds lasts for 6 months and permits rearing of two generation per year. Thus, the selection effects are observed faster in conditions of maximum yields. Figure 3 depicts the 
dynamics in the laying intensity in the three populations (WG, GG and GL groups). It shows clearly higher average values of the trait between the 1st and 5th production weeks. Egg production rate was markedly higher in the lighter GL and GG groups than in WG group. After this period, peak production was maintained until the 21 st -23 rd production week with occasional peaks, more specific in group GL. Between production weeks 23 and 26, egg production declined substantially below $80 \%$ in all groups, more noticeably in group GL. The highest peaks were observed in
LUKANOV H., et al. group GL $-93.85 \%$ during the 14 th production week. There were other average values over $90 \%$ in this group between the 7th and 20th production week. The other two groups, typical representatives of the meat type, did not attain egg production rates over $90 \%$. The highest average weekly production rates in group GG occurred during the 9th production week while in the WG population - during the 11th week, $89.38 \%$ and $84.25 \%$, respectively. These two heavy populations had optimum laying parameters between production weeks 5-21 (GG group) and 7-23 (group WG).

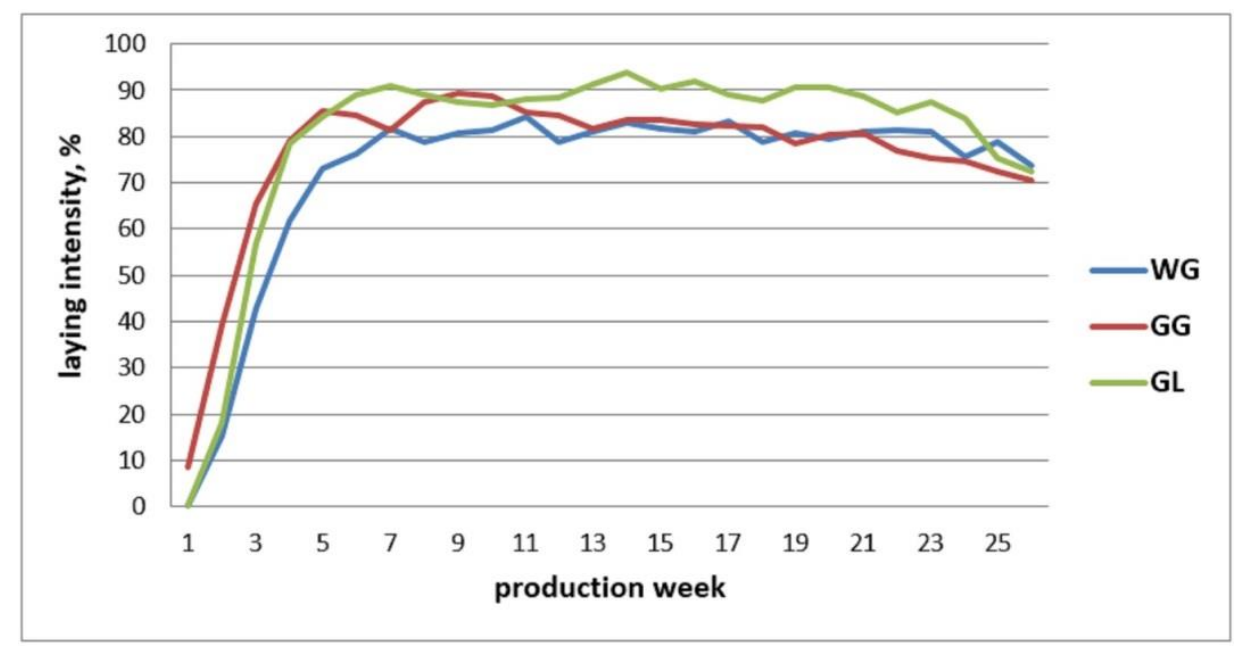

Figure 3. Average weekly laying intensity during the monitoring period, $\%$.

Table 1 presents egg production in the three population characterised by the average monthly laying intensity. The highest monthly laying intensity in groups WG and GL was registered during the 4th month of production $(81.46 \pm 2.87 \%$ vs $90.59 \pm 3.13 \% ; p<0.05)$. The highest values for group GG were in the 2nd and 3rd production months $(85.64 \pm 2.67 \%$ and $85.08 \pm 2.8 \%$, respectively). As the average laying intensity for the entire period was concerned, the highest rates were found out in group GL (79.84 $\pm 4.46 \%$ ), followed by GG $(76.33 \pm 3.40 \%)$ and WG $(72.11 \pm 4.16 \%)$. The values were within the average laying intensity range reported by Pigareva and Afanasiev (8) in Japanese quails. The analysis of the average laying intensity between production weeks 523 outlined with relatively stable egg production rates, showed statistically significantly higher values in group GL ( $88.98 \pm 0.54 \%)$, as compared to both meat-type populations GG and WG, with $82.87 \pm 0.86 \%$ and $80.36 \pm 0.60 \%$ respectively $(\mathrm{p}<0.001)$. Similar data for the egg production in Japanese quails were reported by Genchev and Kabakchiev (9), Genchev (2), Fouladi et al. (10). Mori et al. (11) published comparable yet higher values in meat-type quails, similar to those in our GL group. Santos et al. (12) reported considerably higher laying intensity in meat-type quails than in egg-type birds.

Table 1. Average monthly laying intensity, \%.

\begin{tabular}{|c|c|c|c|c|c|c|c|}
\hline \multicolumn{8}{|c|}{ laying intensity, \% } \\
\hline group/n & $\begin{array}{l}\text { productive } \\
\text { month }\end{array}$ & 1 & 2 & 3 & 4 & 5 & 6 \\
\hline WG/160 & $\mathrm{x} \pm \mathrm{SEM}$ & $38.65 \pm 1.76$ & $79.43 \pm 2.52$ & $81.31 \pm 2.67$ & $81.46 \pm 2.87$ & $80.65 \pm 2.90$ & $77.19 \pm 1.90$ \\
\hline GG/160 & $\mathrm{x} \pm \mathrm{SEM}$ & $55.57 \pm 2.07$ & $85.64 \pm 2.67$ & $85.08 \pm 2.8$ & $82.84 \pm 2.74$ & $79.13 \pm 2.92$ & $73.27 \pm 1.25$ \\
\hline GL/96 & $\mathrm{x} \pm \mathrm{SEM}$ & $47.2 \pm 2.02$ & $87.72 \pm 2.26$ & $88.49 \pm 2.03$ & $90.59 \pm 3.13$ & $85.92 \pm 2.23$ & $80.91 \pm 3.18$ \\
\hline \multicolumn{2}{|c|}{ significance } & $\begin{array}{c}1: 2 * * * ; 1: 3 * * ; \\
2: 3 * *\end{array}$ & $1: 2^{*}$ & NS & $1: 3^{*}$ & NS & $2: 3 * *$ \\
\hline
\end{tabular}


Similarly to live weight and laying intensity, egg weight varied according to the production type. The association was positive with the live weight and negative - with the laying intensity (6). Egg-type quails lay smaller eggs exhibiting higher laying intensity and vice versa; those from the meat-type lay heavier eggs but their laying intensity was lower. Figure 4 shows the change in egg weight by production months for the entire 36-week period. The graph exhibit a clear differences in the trait in the three groups. Statistically significantly highest egg weight was observed in the WG population with peak during the $3 \mathrm{rd}$ month of production $-14.87 \pm 0.15 \mathrm{~g}(\mathrm{p}<0.001)$. That period was outlined also with the highest values in groups GG and GL, with $14.07 \pm 0.18$ $\mathrm{g}$ and $13.68 \pm 0.15 \mathrm{~g}$. Between production months 1 and 2, average egg weight increased in all groups, and thereafter the tendency was preserved although at a lower rate. After the 3rd month, the curve of the trait demonstrated serious fluctuations in WG and GL populations, especially in the latter. The declined average monthly egg weight between months 3 and 5 was $1.28 \mathrm{~g}$, it increased during the 6 th month when the decline was reduced to
0.65 g. The third group (GG) exhibited the most stable trend with respect to the trait. The increase in egg weight parallelly to age is a natural event influenced by several external factors (housing density, sex ratio, ambient temperature, feeding, illnesses etc). The tendency was also mentioned by other researchers on quail egg quality (13-16). Like us, Yilmaz-Dikmen and Ipek (17), Vali et al. (18) and Zita et al. (19) found out lower egg weight by the end of the production cycle. The highest mean egg weight for the period was registered in WG eggs $(14.04 \pm 0.32 \mathrm{~g})$, followed by GG $(13.65 \pm 0.27 \mathrm{~g})$ and GL $(12.79 \pm 0.29 \mathrm{~g})$ eggs. The difference between average egg weights of the lightest population (GL) and the other two heavier ones (WG and GG) was significant $(p<0.05)$. In ancestors of lines WG and GG, Genchev and Kabakchiev (9) reported lower average values of egg weight. In a more recent study, Genchev (2) observed higher values in these populations, comparable to present values. Lower egg weights in meat-type quails were also affirmed by Mori et al. (11), Hrnčár et al. (20), Hanusová et al. (21).

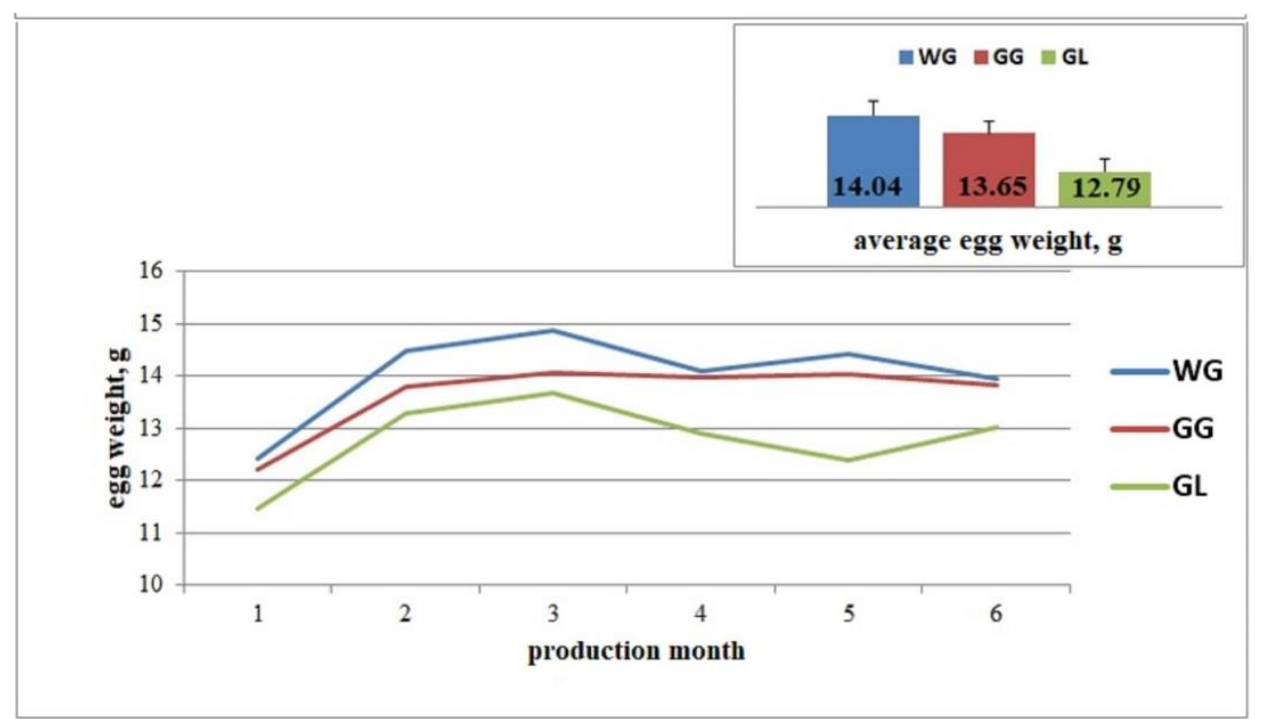

Figure 4. Changes in egg weight according to the production month and average egg weight for the production period, g.

Figure 5 presents the results for culled eggs week by week. In the three groups, culled eggs decreased extensively from the 1 st to the 5th production week along with increase in egg lay intensity. The more pronounced reduction in culled eggs percentage for this early period was observed in group $\mathrm{GG}-32.78 \%$, followed by GL quails with $29.40 \%$. In the heaviest population - WG, normalisation of produced eggs occurred the least rapidly. Similarly, during the last 2-3 production weeks were also characterised with more abnormal eggs, although at a lesser extent. Between weeks 623 , culled eggs in all groups were within the normal range for the species and productive type and varied from $0.93 \%$ and $5.66 \%$. Comparable trend was reported by Genchev and Kabakchiev (9) for Pharaoh and Manchurian Golden quails. These changes in the dynamics of culled eggs could be explained 
with hormonal disbalance at the time of sexual maturation and growth of genitals in female quails. By the end of the production period, the slight increase in culled egg percentage could be attributed to higher ambient temperatures (the beginning of the summer), exhaustion of birds by intensive lay and hormonal changes preceding the production cycle end. A similar pattern of culled eggs distribution was published by Genchev (2) over a 7-month production cycle. The careful analysis of the culled eggs curve shows that its shape is opposite to that depicted on Figure 2. There was not an obvious relationship between egg production of a given population and the proportion of culled eggs. The lowest share of culled eggs between the 6th and 23rd week was found out in group GG $(2.43 \pm 0.23 \%$, $\mathrm{p}<0.01$ ), whose egg production is intermediate with respect to the general one.

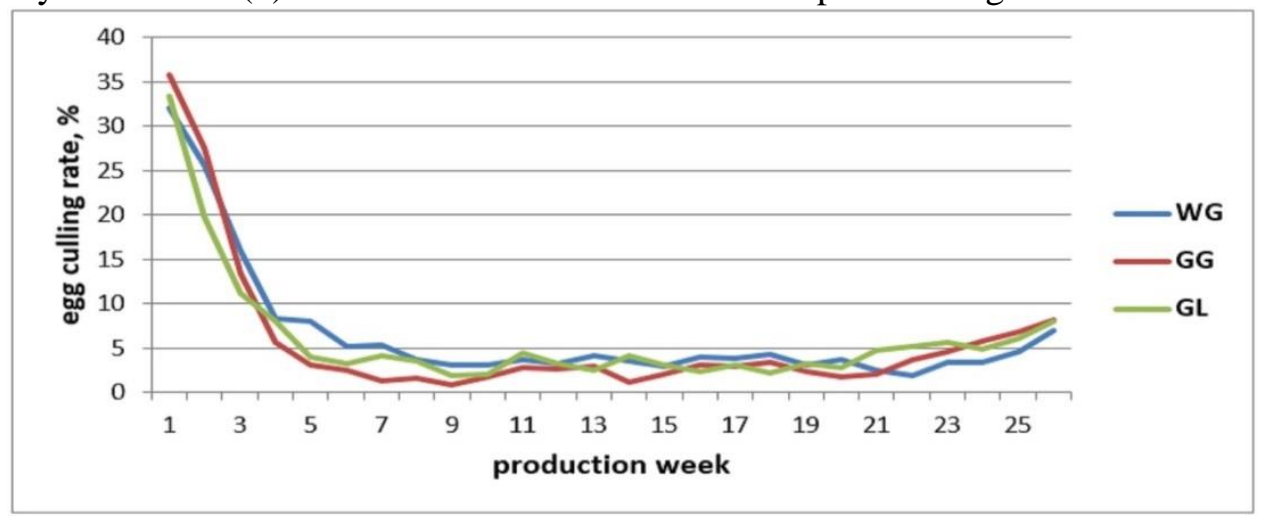

Figure 5. Average weekly egg culling rate, $\%$.

The distribution of abnormal eggs is done in Table 2, where they are divided into three categories - double-yolk, soft-shelled, and others including undersize, with discoloration, cracked etc. The sharp reduction of doubleyolk eggs after the first month of production and the simultaneous increase in discolorated eggs, and eggs with improper shell thickness and shape (the "others' group) should be emphasised. Unlike these two categories which showed large variations during the study period, the proportion of soft-shell eggs remained almost constant in the three groups. It could be argued whether double-yolk eggs should be culled or considered as a regular retail product, they were placed in the abnormal eggs group for several reasons. First, apart for consumption, quail eggs serve also as breeder eggs hence they could not be used for that purpose. The standard stock egg should be with a single yolk and size allowing the proper packaging of the production. The analysis of results suggested that there was a tendency towards higher share of double-yolk eggs in heavier populations compared to the lighter GL group. The lowest average proportion of softshell eggs for the period was observed in group $\mathrm{GG}$, and the other two groups (WG, GL) had similar and slightly higher values. The opposite was found with regard to the average proportion of culled eggs from the "others" category - lowest comparable values in groups WG and GL, and significantly higher: in group GG. Genchev and Kabakchiev (9) and Genchev (2) affirmed a similar time course in percentages of the various abnormal eggs types in two heavy Japanese quail breeds.

Table 2. Distribution of abnormal eggs from the three populations, $\%$.

\begin{tabular}{|c|c|c|c|c|c|c|c|c|c|}
\hline \multirow{3}{*}{$\begin{array}{l}\text { Productive } \\
\text { month }\end{array}$} & \multicolumn{9}{|c|}{ group } \\
\hline & \multicolumn{3}{|c|}{ WG } & \multicolumn{3}{|c|}{ GG } & \multicolumn{3}{|c|}{ GL } \\
\hline & DYE & SSE & other* & DYE & SSE & other* & DYE & SSE & other* \\
\hline 1 & 39.69 & 30.16 & 30.16 & 46.14 & 14.73 & 39.13 & 30.15 & 35.29 & 34.56 \\
\hline 2 & 27.72 & 23.76 & 48.51 & 13.11 & 16.39 & 70.49 & 15.71 & 24.29 & 60.00 \\
\hline 3 & 9.40 & 25.64 & 64.96 & 9.23 & 25.31 & 65.46 & 9.56 & 27.69 & 62.75 \\
\hline 4 & 6.79 & 26.54 & 66.67 & 8.18 & 15.45 & 76.36 & 8.97 & 15.38 & 75.64 \\
\hline 5 & 4.31 & 19.83 & 75.86 & 4.21 & 24.21 & 71.58 & 6.49 & 25.97 & 67.53 \\
\hline 6 & 2.90 & 42.03 & 55.07 & 1.30 & 22.08 & 76.62 & 5.68 & 37.84 & 56.48 \\
\hline average & 15.14 & 27.99 & 56.87 & 13.69 & 19.70 & 66.61 & 12.76 & 27.74 & 59.49 \\
\hline
\end{tabular}

DYE - Double-Yolk Eggs; SSE - Soft-Shell Eggs

*small, cracked, misshaped, rough shelled, depigmented eggs etc. 
Figure 6 and Figure 7 present data for weekly cumulative mortality rates and average monthly mortality in the three quail groups. Culled birds because of oviduct prolapse, fractures, poor general condition, cachexia etc. are included as well. Curves on Fig. 6 demonstrate the gradual increase during the first two-thirds of the laying cycle, followed by a sharp elevation, well pronounced in group GL. A critical period occurred after the 21st production week, accompanied with mortality rates over $15 \%$ in groups GG and GL. Although the GL population exhibited higher mortality until the 21 st week, with respect to the total mortality for the period its death rates were similar and lower as compared to GG quails $-20.91 \%$ and $23.40 \%$. The highest survival was registered in the heaviest population WG $-14.35 \%$ mortality. Our results were within the accepted for industrial farming of the species (8). During the first five
LUKANOV H., et al. production months, the average monthly death rates did not exceed $6 \%$, and for WG quails was even below $3 \%$. During the last month of the cycle, average death rates increased considerably, most obviously in GL and WG. The main cause of mortality in stock layers during the first month of production is oviduct prolapse after attempts for laying double-yolk eggs and the yet insufficient elasticity of vaginal oviduct part. At the end of the production cycle, more common were cases of exhaustion, with higher mortality or culling rates in groups with higher egg production (GL and GG). Mori et al. (11) reported death rates from $9.72 \%$ to $13.89 \%$ for a 168 -day production period in different meat-type quail lines. Genchev (2) reported higher death rates including culling rates, in ancestors of WG and GG populations, with similar mortality curve pattern.

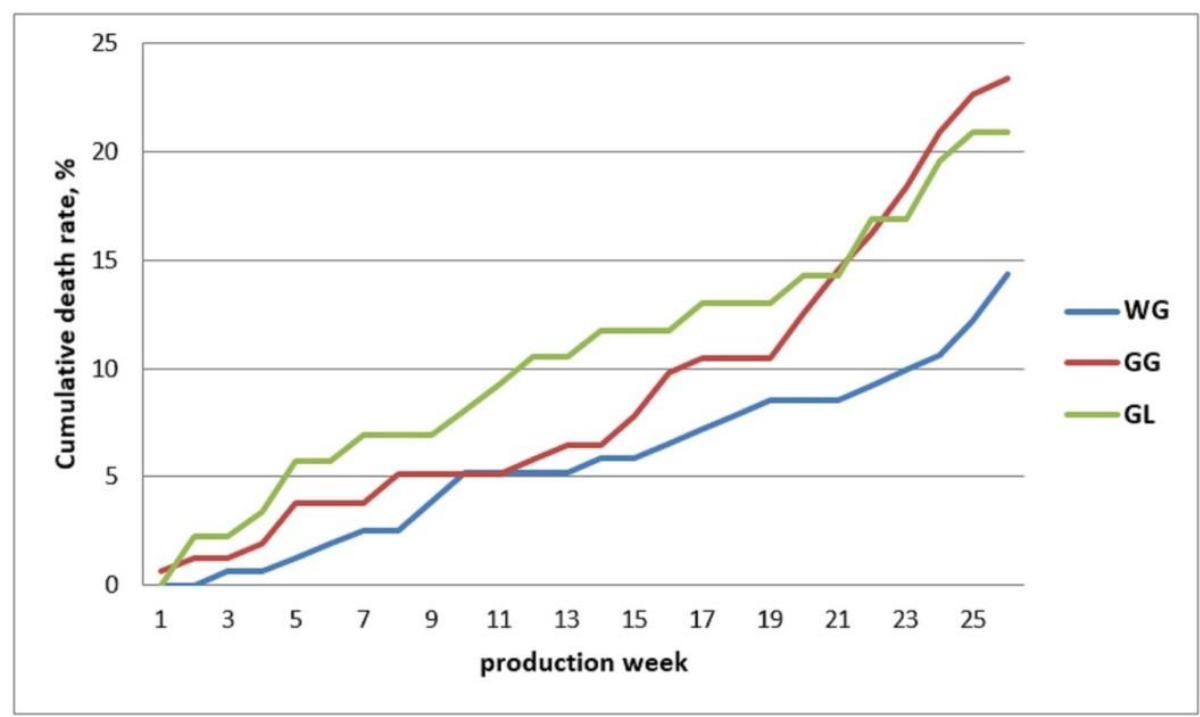

Figure 6. Cumulative death and culled birds rate by production weeks, $\%$.

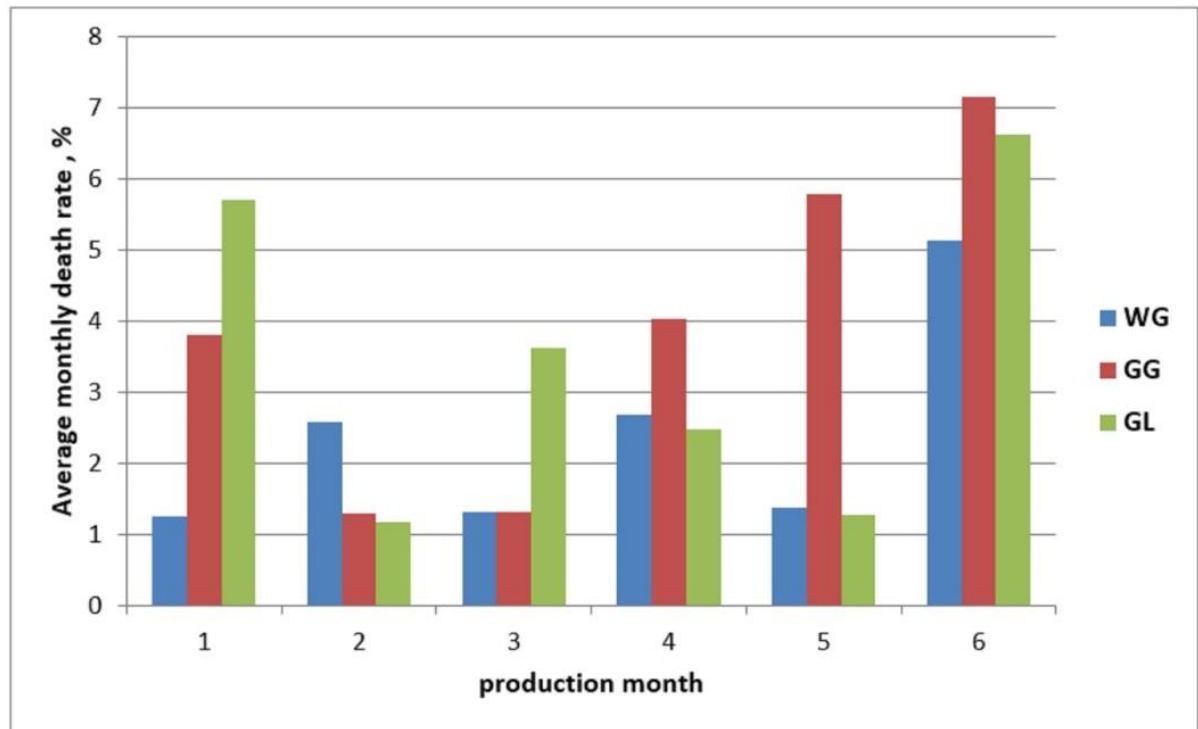

Figure 7. Average monthly death and culled birds rate for the production period, $\%$. 
Table 3 summarised average monthly and general results about daily feed intake and feed conversion in the three populations. Daily feed intake did not vary substantially during the six production months: from $34.59 \pm 0.85 \mathrm{~g}$ in group GG by the end of the cycle to $46.57 \pm 0.89 \mathrm{~g}$ in the same group at the beginning of the cycle. Both heavy populations (WG and GG) tended to have higher average daily feed intake during the first two production months. This could be attributed to the higher proportion of large double-yolk eggs at that time and the yet uncompleted growth. The data for this traits could be related to live weight data in the three groups but not to changes in egg production. This suggest a higher importance of the need from nutrients for maintaining vital functions as compared to the needs for egg production. The highest average feed intake for the period was registered in the heaviest WG group $(42.00 \pm 1.2 \mathrm{~g})$, and the lowest - in GL group $(37.77 \pm 1.08 \mathrm{~g}, \mathrm{p}<0.01)$. Comparable results about average daily feed intake of the GL population were reported by Mori et al. (11) in several meat-type quail lines. Despite the lower body weight of WG and GG ancestors, Genchev (2) established similar values of daily feed intake. In meat-type quails but with live body weight corresponding to the dual-purpose type (240-270 g), Santos et al. (12) reported lower daily feed intake. Comparable results were also reported by Fouladi et al. (10).

Table 3. Feed intake and feed conversion of the three groups during the six production months and average for the entire production period.

\begin{tabular}{ccccccccc}
\hline & \multicolumn{7}{c}{ Average daily feed intake, } \\
\multicolumn{1}{c}{ group } & 1 & 2 & 3 & 4 & 5 & 6 & average \\
\hline \multirow{2}{*}{ WG } & $\mathrm{X}$ & 45.54 & 44.19 & 41.91 & 42.54 & 38.81 & 39.03 & 42.00 \\
& SEM & 1.42 & 1.25 & 1.49 & 1.05 & 0.88 & 1.08 & 1.21 \\
\multirow{2}{*}{ GG } & $\mathrm{X}$ & 46.57 & 45.29 & 40.19 & 42.59 & 39.76 & 34.59 & 41.50 \\
& SEM & 0.89 & 1.53 & 1.19 & 1.24 & 0.94 & 0.85 & 1.93 \\
& $\mathrm{X}$ & 37.21 & 40.65 & 40.20 & 40.70 & 37.09 & 34.86 & 37.77 \\
GL & SEM & 1.35 & 2.22 & 1.71 & 2.55 & 2.33 & 2.62 & 1.08 \\
\multicolumn{2}{l}{ significance } & $1,2: 3^{* * *}$ & $\mathrm{NS}$ & $\mathrm{NS}$ & $\mathrm{NS}$ & $\mathrm{NS}$ & $1: 2^{* *}$ & $1: 3^{* *}$ \\
\hline
\end{tabular}

\begin{tabular}{ccccccccc}
\hline & \multicolumn{7}{c}{ Feed conversion, g/egg } \\
\multicolumn{1}{c}{ group } & 1 & 2 & 3 & 4 & 5 & 6 & average \\
\hline \multirow{2}{*}{ WG } & $\mathrm{X}$ & 80.21 & 73.35 & 78.33 & 75.65 & 71.45 & 67.97 & 74.49 \\
& $\mathrm{SEM}$ & 4.67 & 3.61 & 5.68 & 2.24 & 2.75 & 3.07 & 2.02 \\
$\mathrm{GG}$ & $\mathrm{X}$ & 74.59 & 68.91 & 68.64 & 73.75 & 65.67 & 64.68 & 69.37 \\
& $\mathrm{SEM}$ & 7.14 & 3.21 & 4.14 & 4.58 & 2.93 & 5.11 & 1.82 \\
$\mathrm{GL}$ & $\mathrm{X}$ & 70.66 & 61.67 & 63.23 & 63.39 & 66.00 & 64.65 & 64.93 \\
& $\mathrm{SEM}$ & 6.23 & 5.14 & 4.56 & 7.53 & 5.41 & 6.05 & 1.41 \\
\multicolumn{2}{l}{ significance } & $\mathrm{NS}$ & $\mathrm{NS}$ & $1: 3^{*}$ & $\mathrm{NS}$ & $\mathrm{NS}$ & $\mathrm{NS}$ & $1: 3^{* * *}$ \\
\hline
\end{tabular}

Feed conversion, g/g egg

\begin{tabular}{|c|c|c|c|c|c|c|c|c|}
\hline \multirow{2}{*}{\multicolumn{2}{|c|}{ group }} & \multicolumn{6}{|c|}{ production month } & \multirow[b]{2}{*}{ average } \\
\hline & & 1 & 2 & 3 & 4 & 5 & 6 & \\
\hline \multirow{2}{*}{ WG } & $\mathrm{x}$ & 5.53 & 5.11 & 5.36 & 5.15 & 4.98 & 4.79 & 5.15 \\
\hline & SEM & 0.32 & 0.22 & 0.37 & 0.28 & 0.21 & 0.21 & 0.12 \\
\hline \multirow{2}{*}{ GG } & $\mathrm{x}$ & 5.47 & 4.83 & 4.87 & 5.29 & 4.75 & 4.76 & 5.00 \\
\hline & SEM & 0.48 & 0.20 & 0.26 & 0.28 & 0.21 & 0.36 & 0.14 \\
\hline \multirow{3}{*}{$\begin{array}{l}\text { GL } \\
\text { sign }\end{array}$} & $\mathrm{x}$ & 5.84 & 4.72 & 4.80 & 4.92 & 5.15 & 5.10 & 5.09 \\
\hline & SEM & 0.53 & 0.35 & 0.40 & 0.55 & 0.41 & 0.46 & 0.18 \\
\hline & cance & NS & NS & NS & NS & NS & NS & NS \\
\hline
\end{tabular}

Feed conversion ratio (FCR) is an important economic trait of efficiency of nutrients conversion into produce, here - stock/breeder eggs. The higher FCR values, the less efficient its conversion is and vice versa. In poultry breeding, a more frequently used index is feed 
conversion per $1 \mathrm{~kg}$ produce (meat or eggs). In quail farming, due to the small egg size, FCR is more conveniently calculated on the basis of feed spent for production of one egg. At present, this is justified due to the absence of quail egg categories by size and the equal price of eggs with different size. A more precise indicator is the feed spent for the production of $1 \mathrm{~g}$ egg mass, as the weight of eggs is taken into consideration. As feed intake for production of one egg is regarded, results are not different from what was anticipated - WG quails in which feed intake was the highest and egg production - the lowest, exhibited the most unfavourable FCR. For production of one WG egg, throughout the entire period, $74.49 \pm 1.21 \mathrm{~g}$ feed was necessary. GL quails were characterised with the most efficient feed conversion per egg and the difference between them and WG was $9.56 \mathrm{~g}(\mathrm{p}<0.01)$. It is reasonable to expect the best FCR in the group that consumes the lowest amount of feed and lays the greatest number of eggs. Group GG had an intermediate feed intake per egg vs the other groups $(p>0.05)$. The dynamics of data demonstrated highest average values during the first month of production for the three groups, when egg production has not still attained its peak. During the next production months, no substantial between-group variation in the trait was noted.

More efficient feed conversion for production of one egg was outlined by Mori et al. (11), Santos et al. (12), Fouladi et al. (10) and Genchev (2), by reason of lighter birds and/or better egg production.

When the feed conversion per $1 \mathrm{~g}$ egg mass was however evaluated, the best results were found out in the GG population - 5.00 \pm 0.14 $\mathrm{g} / \mathrm{g}$ egg mass due both the higher laying intensity and egg weight and moderate daily feed intake in this group. The worst feed conversion was that of WG quails by reason of lower egg production and higher daily feed intake than the other two groups, which could not be compensated by the high egg weight.

\section{CONCLUSION}

The results from the investigation allowed suggesting the use of GL population or its autosexing crosses for production of stock quail eggs in the present market situation. WG and GG populations could be successfully used for quail meat production. The future detection of differences in egg weights in the various quail types is desirable as a criterion for price formation of the product. In case of introduction of categorisation of quail eggs on the basis of their weight, the farming of heavytype quails for production of eggs for consumption would be economically justified.

\section{REFERENCES}

1. Howes, J.R., Managing Coturnix quail for research work. Quail Quart, 1 (3-4): 31-40, 1964.

2. Genchev, A., Production characteristics of Japanese quail (Coturnix coturnix japonica) of Pharaoh and Manchurian Golden Quail Breeds. DSc Thesis, Stara Zagora, 2014. (In Bulgarian)

3. Oyewole, O.A., Biogas Production from chickens droppings. Science World Journal, 5 (4): 11-14, 2010.

4. Onursal, E., Oechsner, H. and Ekinci, K., Biogas Production Potential of Rose Oil Processing Wastes and Quail Manure in Turkiye: Assessment by Hohenheim Batch Test. Journal of Agricultural Machinery Science, 7 (4): 393-398, 2011.

5. Elasri, O. and Afilal, M.E.A., Potential for biogas production from the anaerobic digestion of chicken droppings in Morocco. International Journal of Recycling of Organic Waste in Agriculture, 5 (3): 195204, 2016.

6. Genchev, A. and Lukanov, H., Padpadakovadstvo. Stara Zagora, 2018, In Print. (In Bulgarian)

7. Lukanov, H., Genchev, A. and Dragolova, I., Phenotypic Characteristics Of The Gl Sire Line For Production Of Autosexing Japanese Quails. Trakia Journal of Sciences, 1: 40-50, 2018.

8. Pigareva, M.D. and Afanasiev, G.D., Perepelovodstvo. Moscow, Rosagropromizdat, 1989. (In Russian).

9. Genchev, A. and Kabakchiev, M., Egg productivity and egg quality estimation and evaluation of two breeds of Japanese quails (Coturnix japonica). Agricultural Science and Technology, 1: 8-12, 2009.

10.Fouladi, P.I., Ebrahimnezhad, Y.I., Aghdam Shahryar, H.I., Maheri, N.I. and Ahmadzadeh, A.I., Effects of Organic Acids Supplement on Performance, Egg Traits, Blood Serum Biochemical Parameters and Gut Microflora in Female Japanese Quail (Coturnix coturnix japonica). Brazilian Journal of Poultry Science, 20 (1): 133-144, 2018.

11.Mori, C., Garcia, E.A., Pavan, A.C., Piccinin, A., Scherer, M.R. and Pizzolante, C.C., Desempenho e qualidade dos ovos de codorna de quatro grupos genéticos. Revista Brasileira de Zootecnia, 34: 864-869, 2005. 
12.Santos, T.C., Murakami, A.E., Fanhani, J.C. and Oliveira, C.A.L., Production and reproduction of egg- and meat-type quails reared in different group sizes. Brazilian Journal of Poultry Science, 13(1): 9-14, 2011.

13.Orhan, H., Erensayin, C. and Aktan, S., Determining egg quality characteristics of Japanese quails (Coturnix coturnix japonica) at different ages. Hayvansal Üretim, 42 (1): 44-49, 2001.

14.Seker, I., Kul, S. and Bayraktar, M., Effects of parental age and hatching egg weight of Japanese quails on hatchability and chick weight. International Journal of Poultry Sciences, 3: 259-265, 2004.

15.Johnston, S.A. and Gous, R.M., Modelling the changes in the proportions of the egg components during a laying cycle. British Poultry Science, 48 (6): 347-353, 2007.

16. Wilkanowska, A. and Kokoszyński, D., Layer Age And Quality Of Pharaoh Quail Eggs. Journal of Central European Agriculture, 13 (1): 10-21, 2012.

\section{LUKANOV H., et al.}

17.Yilmaz-Dikmen, B. and Ipek, A., The Effects of shank length on egg production and Egg quality traits of Japanese quails (Coturnix coturnix japonica). EPC 2006XII European Poultry Conference, Verona, Italy, September 10-14, 2006.

18. Vali, N., Edriss, M.A. and Moshtaghi, H., Comparison of egg weight between two quail strains. International Journal of Poultry Sciences, 5: 394-400, 2006.

19.Zita, L., Ledvinka, Z., Tumova, E. and Klesalova, L., Technological quality of eggs in relation to the age of laying hens and Japanese quails. Revista Brasileira de Zootecnia, 41 (9): 2079-2084, 2012.

20.Hrnčár, C., Hanusová, E., Hanus, A. and Bujko, J., Effect Of Genotype On Egg Quality Characteristics Of Japanese Quail (Coturnix Japonica). Slovak Journal of Animal Science, 47 (1): 6-11, 2014.

21.Hanusová, E., Hrnčár, C., Hanus, A. and Oravcová, M., Egg traits in Japanese quails. Acta Fytotechnica et Zootechnica, 19 (Special Issue): 62-67, 2016. 